\title{
Extent of Inflammation and Foreign Body Reaction to Porous Polyethylene In Vitro and In Vivo
}

\author{
TOBIAS VOLLKOMMER ${ }^{1 *}$, ANDERS HENNINGSEN ${ }^{1,2,3^{*}}$, REINHARD E. FRIEDRICH $^{1}$, \\ OLIVER HEINRICH FELTHAUS ${ }^{4}$, FABIAN EDER ${ }^{5}$, CHRISTIAN MORSCZECK $^{6}$, \\ RALF SMEETS $^{1,2}$, SEBASTIAN GEHMERT ${ }^{7}$ and MARTIN GOSAU ${ }^{1}$ \\ ${ }^{I}$ Department of Oral and Maxillofacial Surgery, \\ University Medical Center Hamburg-Eppendorf, Hamburg, Germany; \\ ${ }^{2}$ Department of Oral and Maxillofacial Surgery, Division of Regenerative Orofacial Medicine, \\ University Medical Center Hamburg-Eppendorf, Hamburg, Germany; \\ ${ }^{3}$ Department of Oral and Maxillofacial Surgery, German Armed Forces Hospital, Hamburg, Germany; \\ ${ }^{4}$ Department of Plastic, Hand and Restoration Surgery, Caritas Hospital St. Josef, Regensburg, Germany; \\ ${ }^{5}$ Private practice, Regensburg, Germany; \\ ${ }^{6}$ Department of Oral and Maxillofacial Surgery, University Medical Center-Regensburg, Regensburg, Germany; \\ ${ }^{7}$ Department of Orthopaedics, University Children's Hospital Basel, Basel, Switzerland
}

\begin{abstract}
Background/Aim: High-density porous polyethylene $(P P)$ offers possibilities for reconstruction in craniofacial surgery. The purpose of this study was to evaluate the extent of inflammation and foreign body reactions to PP in vitro and in vivo. Materials and Methods: Cell attachment, proliferation and expression of inflammatory cytokines were assessed using murine macrophages (RAW 264.7) on two different PP materials in vitro. In vivo, Balb/c mice received $P P$ implants at their dorsum. After sacrifice, samples were analyzed histologically and real-time PCR was used to assess expression of inflammatory cytokines. Results: Cells showed a significantly decreased proliferation $(p<0.001)$ after $48 \mathrm{~h}$ and a significantly increased expression of TNF- $\alpha(p<0.05)$ at 24 , 48 and $72 \mathrm{~h}$. All animals showed foreign body cell reactions and signs of chronic inflammation. Expression of all but one of the investigated cytokines dropped to non-significant levels after an initial increase. Conclusion: Application of porous polyethylene can cause local chronic inflammatory reactions. Although clinical application seems to be immunologically
\end{abstract}

This article is freely accessible online.

*These Authors contributed equally to this study.

Correspondence to: Anders Henningsen, Department of Oral and Maxillofacial Surgery, University Medical Center HamburgEppendorf, Hamburg, Germany. E-mail: a.henningsen@uke.de

Key Words: Polyethylenes, foreign-body reaction, macrophages, cytokines, biomaterials. safe, indication and risks should be evaluated carefully when using PP implants.

Porous polyethylene (PP) is an alloplastic material commonly used in craniofacial reconstruction (1-4), and is manufactured from high-density pure polyethylene (HDPPE) that is sintered to create a series of consistent interconnecting pores [average pore size $150 \mu \mathrm{m}$ ], while maintaining a flexible framework (5). The material is rigid, but moldable and available in various shapes, sizes, and thicknesses $(6,7)$. It may be used for the reconstruction of the orbital floor, the ear, the chin and the nose $(3,8-15)$. Surgical implants in humans are being clinically evaluated for more than 20 years $(5,16,17)$. The most important advantages of porous polyethylene are: not resorbable, lack of donor site morbidity, nearly unlimited availability and demonstrating long-term structural stability when used as a facial skeleton onlay (18-22). In a recent review concerning alloplastic materials in rhinoplasty, PP was associated with good aesthetic and functional outcomes and low overall complication rates of $6 \%$ compared to $14 \%$ using autologous costal cartilage (23). However, the use of implants made of PP in craniofacial reconstructive surgery bears the risk of extrusion, infection and migration $(24,25)$.

Rapid ingrowth of blood vessels and low inflammatory response are considered major requirements for successful and long-term integration of biomaterials in reconstructive surgery (26). Implants made of PP may be able to meet these requirements $(27,28)$.

Host immune response is an usual and critical reaction to implantation and presence of artificial materials. The process of biomaterial integration takes place in the following stages: 
injury, provisional matrix formation, acute inflammation, chronic inflammation with granulation tissue development, foreign body reaction and fibrous capsule development (29). Host immune and inflammatory responses are mainly determined by macrophages which are the dominating infiltrating immune cells at the tissue-material interface responding to biomaterial implantation. They are able to unite into multinucleated foreign body giant cells (FBGC) as a terminal state of differentiation and development in the monocyte/macrophage system (30). These cells either try to ingest large particles by phagocytosis or remain at the materialtissue interface releasing cytokines in order to regulate adaptive immune responses, participate in tissue regeneration or induce extracellular biodegradation consecutively leading to implant failure if particles exceed a certain size (31).

Histological investigations of samples in animal studies and of explanted implants in humans have not demonstrated evidence for implant degradation and foreign body reaction has been regarded as minimal or missing $(28,32)$. Several clinical studies have reported low complication rates and favorable outcomes using PP under the assumption of sufficient soft tissue covering $(14,15)$. However, cases with unexpected intense foreign body reaction containing multinucleated giant cell infiltration and focal disintegration of the implant material have also been previously described in several studies evaluating the clinical use of PP implants as augmentation material in the facial skeleton (33-35). Only few studies have evaluated the biocompatibility of PP.

The purpose of the present study was to evaluate of the extent of inflammation and foreign body reactions to PP in vitro and in vivo. Two different PP materials were used to evaluate cell attachment and morphology and cell proliferation of murine macrophage-like cells in vitro. Expression of cytokines (IL-2, IL-12, IL-13 and TNF- $\alpha$ ) was determined in order to assess cellular inflammatory reaction to PP. The same materials were used in a mouse model in order to evaluate inflammation and foreign body reaction histologically and immuno-histologically in tissue samples.

\section{Materials and Methods}

Test and control materials. Ethylenoxide sterilized Medpor (Porex Surgical, Newnan, GA, USA) (Figure 1A) and ethylenoxide sterilized SynPor (DePuy Synthes, Zuchwil, Switzerland) (Figure 1B) samples, $6 \mathrm{~mm}$ in diameter and $1 \mathrm{~mm}$ in thickness, were used for in vitro and in vivo experiments as test materials. Blank wells without samples were used as negative controls in vitro. Pure latex beads, $0.1 \mathrm{ml} ; 0.6 \mu \mathrm{m}$ particle size (Sigma Aldrich, Munich, Germany) were used as positive controls in vivo.

Cell culture. For all in vitro experiments, a murine macrophage cell line (RAW 264.7, Sigma Aldrich) was used. Cells were cultured in RPMI 1640 medium (Sigma Aldrich) supplemented with 10\% fetal bovine serum (PAA, Pasching, Austria) and 100 units/ml penicillin/ $100 \mu \mathrm{g} / \mathrm{ml}$ streptomycin (Sigma Aldrich). Cells were incubated in a humified atmosphere of $95 \%$ air and $5 \% \mathrm{CO}_{2}$ at $37^{\circ} \mathrm{C}$ and seeded at a density of $5.0 \times 10^{4} / \mathrm{cm}^{2}$ in 96 -well plates.

Cell attachment and morphology. After $48 \mathrm{~h}$ of incubation, cells were fixed with $2.5 \%$ glutaraldehyde for $20 \mathrm{~min}$ at room temperature. Cell attachment was qualitatively assessed using scanning electron microscopy (Quanta FEG 400, FEI Company, Hillsboro, OR, USA).

Cell proliferation. Proliferation was assessed using the WST-1 cell proliferation test kit (Roche, Mannheim, Germany). Measurements were conducted in quintuplicates. Cells were seeded directly onto the PP test samples or into the control wells. After incubation for 24 or $48 \mathrm{~h}$, WST-1 reagent was added to the wells. After two hours of incubation, the extinction at $540 \mathrm{~nm}$ was measured in a TECAN infinite F200 plate reader (TECAN, Crailsheim, Germany).

Enzyme linked immunosorbent assay. Cell culture supernatant was collected after 24,48 and $72 \mathrm{~h}$ of incubation and used for enzymelinked immunosorbent assay (ELISA). Mouse IL-2 ELISA Kit, Mouse IL-12p40 ELISA Kit, Mouse IL-13 ELISA Kit and Mouse TNF- $\alpha$ ELISA Kit (all ELISA kits; Invitrogen, Thermo Fisher Scientific, Waltham, MA, USA) were used according to the manufacturer's instructions. Cell culture experiments were performed in groups of five and repeated five times.

Animals. The animal study was approved by local authorities (Authority of Environment, Health and Consumer Protection, Regensburg, Germany; approval number 54-2532.1-07/11) and was conducted following the ARRIVE guidelines (36). Balb/c mice (Charles Rivers Labs, Sulzfeld, Germany), aged 10-12 weeks, with a body weight of 22-25 g were used for in vivo experiments. The animals were kept in numbers of three to five and always had free access to water and pellet food (Altromin, Lage, Germany). Animals were allowed to acclimatize for one week under pathogen free conditions in a controlled environment at the animal facility of the University of Regensburg. All experiments were conducted in accordance with the German legislation on protection of animals and the NIH (USA) Guidelines for the Care and Use of Laboratory Animals (37).

Group distribution. Animals were randomly assigned to 5 different groups. Each group consisted of 20 mice. Group 1 served as a negative control and consisted of animals that were treated and operated like the animals in the other groups, but no materials were inserted. All other animals received one sample on each side of their backs. The animals of group 2 received 2 latex beads as positive control. Group 3 consisted of animals that received 2 Medpor samples, whereas the mice in group 4 received 2 Synpor samples. The animals of group 5 received 1 Medpor and 1 Synpor sample, respectively. Test samples in group 5 were incidentally assigned to the animals back sides. The animals of each group were randomly divided into 4 subgroups ( 5 animals each). The mice in the subgroups were sacrificed after 1 week, 4 weeks, 3 months or 6 months.

Surgical procedures. Mice were anaesthetized by intraperitoneal (i.p.) injection of ketamine $(75 \mathrm{mg} / \mathrm{kg}$ body weight; Pharmacia $\mathrm{GmbH}$, Erlangen, Germany) and xylazine $2 \%(15 \mathrm{mg} / \mathrm{kg}$ body weight; Rompun, Bayer; Leverkusen, Germany). All surgical procedures were performed under sterile conditions. First, animals were placed in a ventral position and the dorsum was shaved on the lower back area followed by disinfection using $70 \%$ ethanol. A 

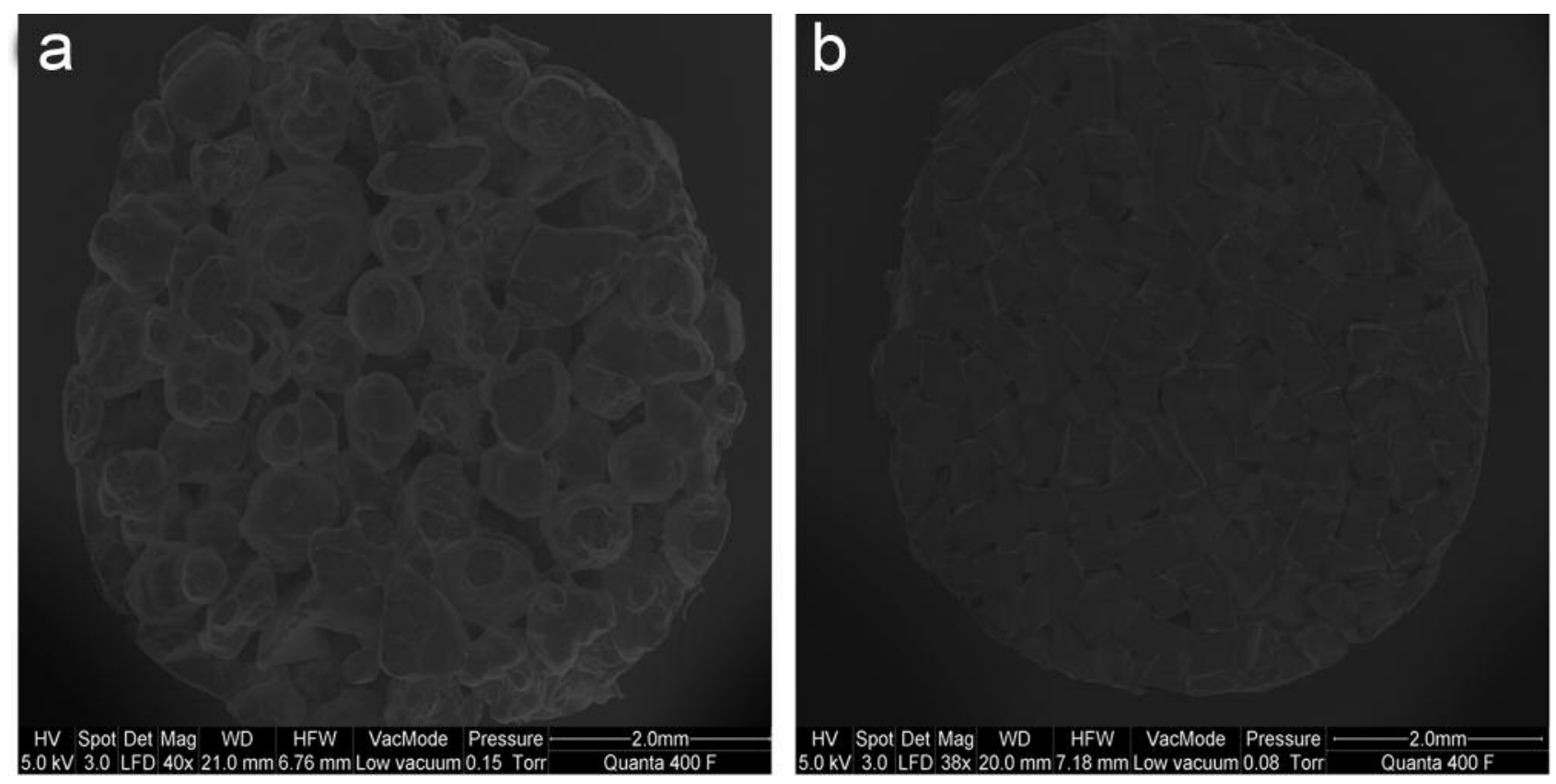

Figure 1. Scanning electron microscopy images of Medpor (a) and SynPor (b) samples, measuring 6 mm in diameter. Note the different microstructures of Medpor (rather round shaped ultrastructure) and Synpor (rather square shaped ultrastructure).

cutaneous incision of $1.5 \mathrm{~cm}$ length was performed at the dorsal part of the animal's back. Two subcutaneous pockets were created in a distance of $2 \mathrm{~cm}$ anterior to the incision by blunt dissection at the lateral aspect on both sides of the spine, in the appropriate plane below the panniculus carnosus. All wounds were closed in a single layer with interrupted 5-0 polypropylene sutures. Animals were followed closely for signs of infection, seroma, or hematoma. Sacrifice was conducted by an anaesthetic overdose.

Histological analysis. Histological sections were analyzed by two pathologists who were not aware of the study's purpose. After sacrifice, the test and control samples were removed containing the surrounding soft tissue and cut into two equal parts. One part of explanted samples was fixed with formalin, embedded into paraffin and stained with haematoxylin and eosin $(\mathrm{H} / \mathrm{E})$. The remaining part was embedded into methacrylate before $\mathrm{H} / \mathrm{E}$ as well as CD68 antibody (Sigma Aldrich) staining. Antibody staining was used to identify macrophages and foreign body giant cells in order to proof phagocytosis of PP material. Sections of $4-\mu \mathrm{m}$ thickness were used in all staining protocols. In addition to these procedures, the spleen was removed from all animals for further analyses.

Six sequential slices were examined from both the paraffin embedded and the methacrylate embedded material of each sample. The following histological criteria were analyzed semi quantitatively by a multi-tiered process: acute inflammatory reaction (neutrophil granulocytes), chronic inflammatory reaction (lymphocytes and plasma cells), presence of foreign body giant cells, intracytoplasmic phagocytosis of small disintegrated foreign material particles and the presence of focal defects or fragmentation of the sample structure. Inflammation was graded by the degree of infiltration of inflammatory cells such as neutrophils, basophils and sporadic mononuclear cells (acute inflammation) or mainly mononuclear cells such as monocytes, macrophages, lymphocytes or plasma cells into peri-implant tissues. Grades were assigned as follows: none=no signs of inflammation; lowgrade=mild inflammation containing occasional appearance of the cells mentioned above; medium-grade=moderate inflammation with frequent infiltration of the cells mentioned above. Fibrovascular obliteration of the PP pores was evaluated as complete versus incomplete.

RNA isolation, reverse transcription and real-time PCR. Total RNA (ribonucleic acid) from murine spleens was isolated using the RNeasy ${ }^{\circledR}$ Plus Mini Kit (Qiagen, Hilden, Germany) according to the manufacturer's protocol. One microgram RNA was reversetranscribed using the QuantiTect ${ }^{\circledR}$ Reverse Transkription Kit (Qiagen) according to the manufacturer's protocol. SYBR Green JumpStart Taq ReadyMix (Sigma Aldrich) was used for quantitative PCR (polymerase chain reaction). Real-time PCR was assessed using a Mastercycler ep gradient $\mathrm{S}$ thermal cycler (Eppendorf, Hamburg, Germany). Primer sequences are listed in Table I. Glyceraldehyde-3-phosphate (GAPDH) was used as a reference gene. Relative gene expression was measured using the $\Delta \Delta \mathrm{Ct}$ method. Experiments were conducted in quadruplicates.

Statistical analysis. All statistical analyses were performed using SPSS 20 (IBM, Armonk, NY, USA). Student's $t$-test was used to compare differences between the test groups and the control groups. $p$-Values $<0.05$ were regarded as statistically significant.

\section{Results}

Cell attachment and morphology. RAW 264.7 cells attached to the surfaces of both materials. Representative images after $48 \mathrm{~h}$ of incubation are shown in Figure 2. Generally, the 
Table I. Real-time PCR primer sequences.

\begin{tabular}{ll}
\hline GAPDH forward & GGTCGGTGTGAACGGATTTG \\
GAPDH reverse & TTTGCCGTGAGTGGAGTCAT \\
IL-6 forward & TCCTCTCTGCAAGAGACTTCC \\
IL-6 reverse & TTGTGAAGTAGGGAAGGCCG \\
IL-12 forward & GTGTCAATCACGCTACCTCCT \\
IL-12 reverse & GAGACTGGAATGACCCTGGC \\
INF- $\gamma$ forward & CGGCACAGTCATTGAAAGCC \\
INF- $\gamma$ reverse & TGTCACCATCCTTTTGCCAGT \\
TNF- $\alpha$ forward & TAGCCCACGTCGTAGCAAAC \\
TNF- $\alpha$ reverse & ACAAGGTACAACCCATCGGC
\end{tabular}

GADPH: Glyceraldehyde-3-phosphate; IL: interleukin; INF: interferon; TNF: tumor necrosis factor.

number of cells attached to the surfaces of PP materials was moderate. Cells on Synpor showed a better attachment with an elongated morphology and increased intercellular contact.

Cell proliferation. After $24 \mathrm{~h}$ in culture, WST-1 incorporation of murine macrophages cultured on PP were lower compared to controls. Differences were not significant. After $48 \mathrm{~h}$ of incubation, a significant decrease $(p<0.001)$ in WST-1 incorporation into mouse macrophages was observed on both PP implant materials indicating a decrease in proliferation (Figure 3).

Cytokine expression in vitro. Expression of TNF- $\alpha$ was significantly increased during cultivation of RAW cells on both PP materials (Figure 4). TNF- $\alpha$ expression was higher in cells cultured on Medpor than on Synpor at any time. However, differences between both materials were not significant.

Expression of IL-2 was slightly but not significantly increased after $24 \mathrm{~h}$ and decreased after $48 \mathrm{~h}$ on both PP materials. IL-2 expression was always higher in cells cultured on Medpor, however, without significant differences. IL-12 expression was significantly increased after $48 \mathrm{~h}$ of incubation on both PP materials with significant differences between Medpor and Synpor. However, after $72 \mathrm{~h}$ of incubation, expression of IL-12 was decreased again, reaching the lowest values on Synpor. Expression of IL-13 on both PP materials increased significantly up to $48 \mathrm{~h}$ of incubation, and on Medpor up to $72 \mathrm{~h}$ of incubation. However, IL-13 expression was significantly decreased on Synpor after $72 \mathrm{~h}$ of incubation. In contrast to Medpor, expression of TNF- $\alpha$ was significantly increased on Synpor after $72 \mathrm{~h}$ of incubation, but values of IL-2, IL-12 and IL-13 were significantly decreased.

Histological analysis of inflammation, integration, foreign body reaction and disintegration. Five animals of the test groups died prior to the study end due to unknown reasons. No animal died in the control groups. Coherence with the implant materials seems to be unlikely but cannot be excluded. All surviving animals showed clinically good health. Generally, only low-grade signs of acute inflammation were seen in the negative control group one week after surgery. After 4 weeks, 3 months and 6 months there were no signs indicating an acute inflammation as well as no signs of chronic inflammation in the negative control group. All animals in the group that received latex beads showed histological signs of low-grade acute inflammation 1 week after surgery. Low-grade chronic inflammatory signs were present in all animals of the positive control group after 3 and 6 months.

Signs of acute inflammation were determined predominantly in the Synpor group (9/10 animals) rather than in the Medpor group (4/10 animals) one week after surgery. However, neutrophil granulocytes and signs of acute inflammation decreased over time to a non-relevant level after 3 to 6 months (Table II). Histological imaging revealed complete fibrovascular obliteration accompanied by an intense vascularization in all animals of both PP test groups after 3 and 6 months (Figure 5). At least low-grade chronic inflammation as well as foreign body giant cell reactions were seen in all animals after 3 months. The highest intensity of foreign-body giant cells was determined after 6 months in the Synpor test group (7/9 animals) combined with chronic inflammation in $1 / 3$ of the animals (3/9 animals). Intracytoplasmic phagocytosis of small disintegrated PP particles was seen in $30-56 \%$ of all animals after 3 and 6 months with an almost equal distribution between Medpor and Synpor. Focal destruction or disintegration of the structure of the PP material was predominantly seen after 3 months in more than $70 \%$ of all animals and to a lesser extent in the 1-week and 6-months group. However, nearly no signs of disintegration or focal destruction were found in the 4-weeks PP test groups.

Cytokine expression in vivo. Generally, animals in the Medpor group showed a higher increase in systemic cytokine expression than animals in the Synpor group (Figure 6). Systemic cytokine expression in the Synpor group was only slightly elevated compared to controls at any time. Animals in the Medpor group showed a steady statistically significant increase in the expression of IL-6 $(p<0.001)$, IL-12 $(p<0.001)$ and INF- $\gamma \quad(p<0.001)$ compared to controls as well as compared to Synpor up to 12 weeks. Especially the expression of IL-12 and INF- $\gamma$ was significantly increased in the Medpor group after 12 weeks. However, 24 weeks after placement of Medpor implants, only expression of IL-6 was significantly increased $(p<0.001)$. The expression of TNF- $\alpha$ was not upregulated, neither in the Medpor nor in the Synpor group.

\section{Discussion}

In the literature, the use of porous polyethylene as a facial reconstruction material has been discussed controversially. On the one hand, PP has been evaluated for a long period of time 

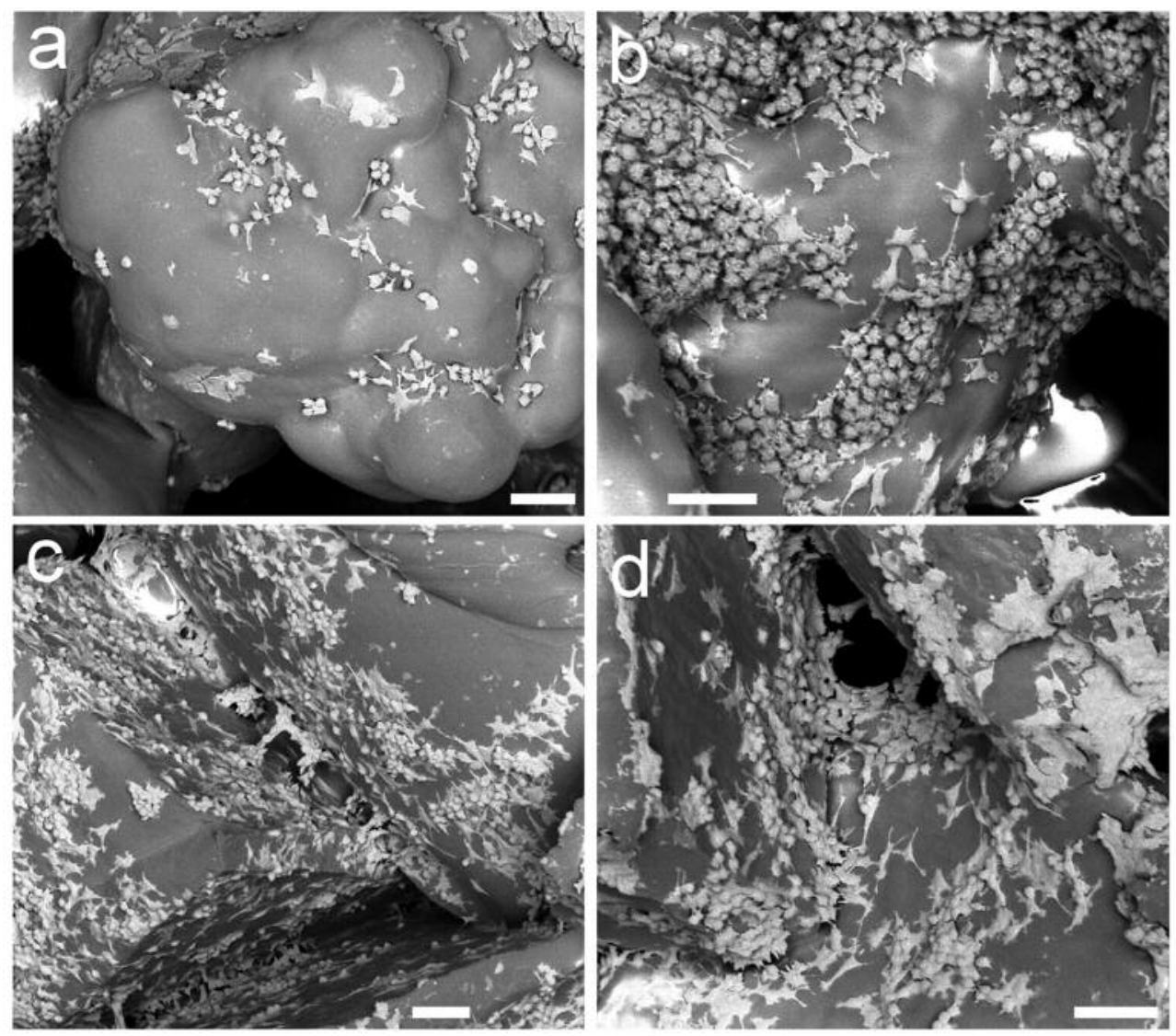

Figure 2. Electron microscopy of RAW 264.7 cells cultured on Medpor $(a ; b)$ and SynPor $(c ; d)$. Bar equals $50 \mu m$.

and offers excellent material properties. On the other hand, the application may lead to infection, exposition or migration. Chronic inflammation and foreign body reactions are key factors for long-term failure or success. The present study aimed to investigate the local and general inflammatory response towards two different $\mathrm{PP}$ implant materials in vitro and in vivo.

The results of the present study suggest that implantation of PP may lead to chronic inflammation as well as foreign body giant cell reaction over a long period of time. Although signs of acute inflammation and cytokine expression may decrease, this study showed an increase in fibrovascular obliteration over time accompanied by an intense vascularization in all animals without major differences between Medpor and Synpor.

The main limitation of this study is clearly that it is an in vivo characterization and the clinical implication of the determined inflammatory reactions has to be evaluated in clinical studies. RAW 264.7 cells, a murine macrophage cell line, were used for all in vitro experiments. They represent a reliable and viable way to test the response to biomaterial implantation in vitro (38). However, recent studies suggest that macrophage subtypes may also be necessary for proper integration of non-degradable biomaterials in vivo (39). Due to low costs, availability and easy handling, rodents are popular experimental models to study performance of biomaterials in vivo. However, murine healing and response to biomaterials does not exactly reflect response to biomaterials in human or in larger animals (40). In human or larger animals, inflammatory reactions and foreign body reactions could be even worse.

In the first part of this study, in vitro biocompatibility testing using murine macrophages was performed. Macrophages were chosen because of their pivotal role in directing host immune and inflammatory response (41). They dominate the response to biomaterial implantation and they are capable of fusing into multinucleated foreign body giant cells (FBGC) (29). Foreign materials induce a differentiation of macrophages into M1- or M2-subtypes (42). Differentiation into M2 subtypes may also be favourable to biomaterial remodelling (43). In the in vitro part of this study, macrophages adhered to the PP surfaces, but proliferation was significantly reduced compared to controls after $48 \mathrm{~h}$ of incubation without significant differences 


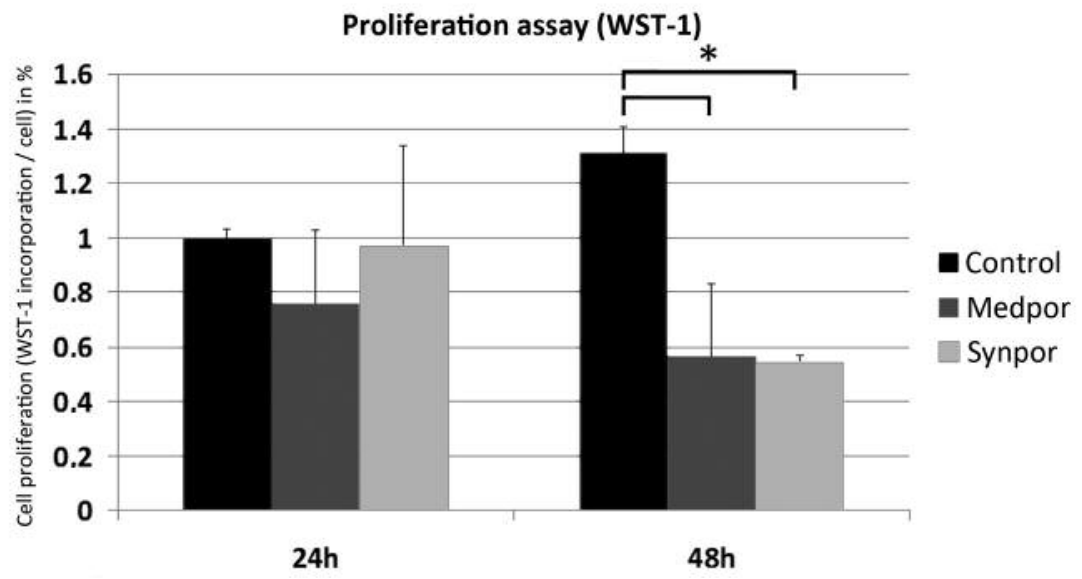

Figure 3. Cell proliferation (WST-1 assay) of RAW cells 24 and 48 h after seeding on Medpor, Synpor and in control wells \pm standard deviation; $* p<0.05$

\section{Cytokine expression in vitro}

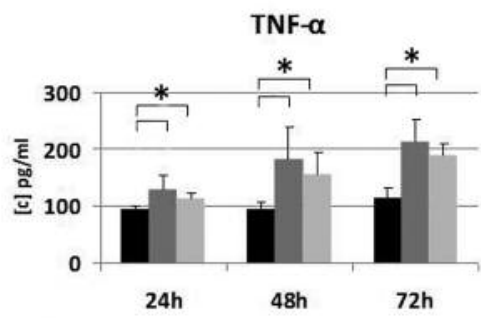

IL-2
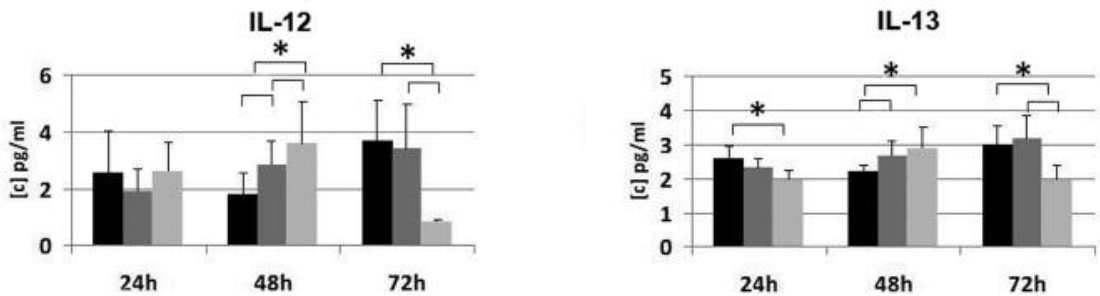

- Control

- Medpor

= Synpor

Figure 4. Expression of inflammation marker genes in the supernatant of RAW cells cultivated on Medpor and Synpor after 24, 48 and $72 \mathrm{~h}$ of incubation \pm standard deviation; $* p<0.05$.

between the PP materials. This may indicate an antiproliferative effect of PP on macrophages. Cell growth may be reduced on polyethylene surfaces due to its hydrophobic properties (44). However, proliferation of macrophages was accompanied by a significant increase in TNF- $\alpha$ expression during cultivation. Phagocytosis of small polyethylene particles by macrophages is a known phenomenon in orthopedic surgery (45). It causes release of inflammatory mediators (TNF- $\alpha$, IL-1, IL-6 etc.). Increased cytokine release may e.g. lead to increased bone resorption and aseptic loosening of arthroplasties (46). Especially the release of TNF- $\alpha$ may result in increased osteoclast formation and activation (47). Generally, the inflammatory response in vitro was slightly greater towards Medpor than towards Synpor in this study, but, however, release of IL-2, IL-12 and IL-13 was not increased for longer than $48 \mathrm{~h}$.

Implantation of biomaterials leads to induction of proinflammatory and wound-healing signaling cascades. Usually, this process results in a more or less severe foreign body reaction depending on the origin and biocompatibility of the 
a

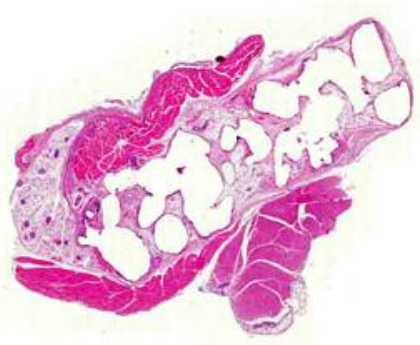

d

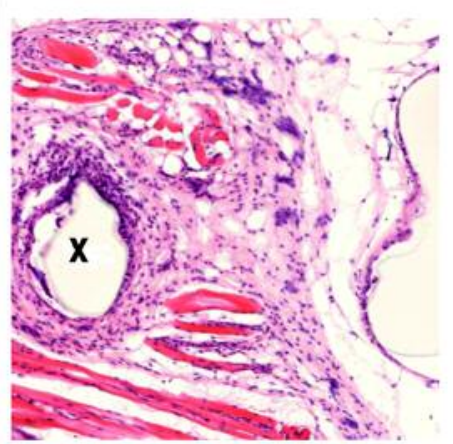

b

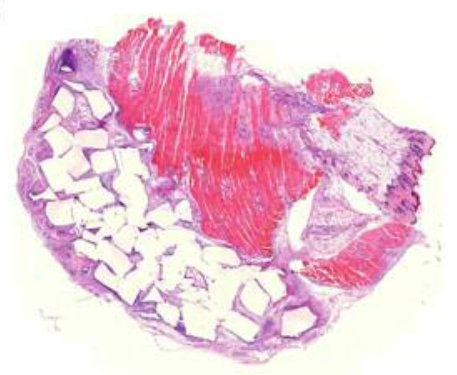

e

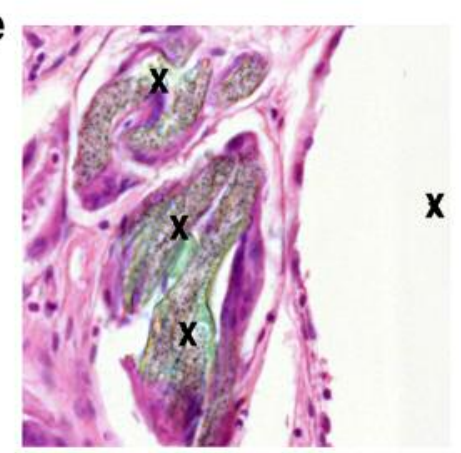

C

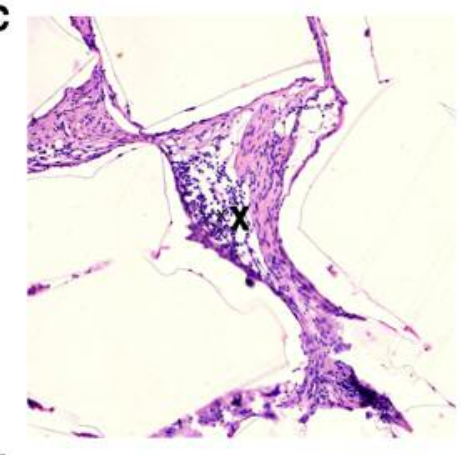

f

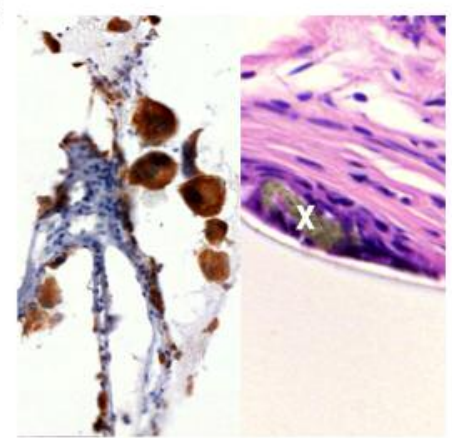

Figure 5. Histology, H\&E staining (except immunostaining against CD68 in f, left side). $a, b$ : Representative microphotographs of a Medpor (a) and a Synpor (b) implant (10x magnification). c: Complete fibrovascular obliteration of implant pores and a sparse inflammatory infiltrate $(X)$ of mainly lymphocytes and plasma cells (100x magnification). d: Remaining space $(X)$ of a small disintegrated implant particle (100x magnification). $e$ : Foreign body giant cells showing phagocytosis of preserved implant particles (X) (400x magnification). $f$ : Immunohistochemical staining against CD68 highlights numerous macrophages and foreign body giant cells (left side of the image, 100x magnification). Histiocytic margin around implant material with phagocytosis of a preserved implant particle $(X)(400 \times$ magnification).

implant and is characterized by multinucleated foreign body giant cells as a terminal state of differentiation in the monocyte and macrophage system $(35,48)$. This study revealed an only moderate acute inflammatory response in vivo that decreased after 4 weeks. By three months, nearly all animals showed an at least low-grade chronic inflammation that was accompanied by an intense foreign body giant cell reaction. In up to $56 \%$ of all animals, phagocytosis of disintegrated PP particles accompanied by focal destruction or disintegration was found. After three months, all implants showed complete fibrovascular obliteration. Several studies also focused on the histological effects of PP in vivo. Morton and colleagues placed $0.85-\mathrm{mm}$ thick implants made of PP in the eyelids of rabbits in order to assess the tolerance and incorporation of PP (6). In a follow-up of 14 to 17 weeks, they found no extrusions but a complete fibrovascularization as early as four weeks after implant placement. Histologically, they found only moderate signs of inflammation at week 1 and only mild signs of inflammation at weeks 2 and 6 . However, the authors did not distinguish between acute and chronic inflammation. In another study, Lee and Baek used alloplastic implants made of PP or absorbable copolymer (Macropore) to reconstruct orbital floor fractures in a rabbit model (10). Animals were sacrificed 1, 2 or 6 weeks after implantation and similarly to the study by Morton et al. they found only mild to moderate signs of inflammation. They observed complete fibrovascular ingrowth in the PP group after 2 weeks, but no ingrowth in the absorbable copolymer implant. They concluded that implants made of PP might be more suitable for orbital floor reconstruction when there are risks of migration or extrusion. In a retrospective study, histopathological findings of 18 explanted PP orbital implants were analyzed (49). The interval from implant placement to removal ranged from 3 months to 7.2 years. Implants showed less than $50 \%$ fibrovascular ingrowth in 16 implants (89\%) and acute or mixed inflammation in 15 implants $(83 \%)$. The authors observed foreign body giant cells attached to the implant surfaces in all cases. However, nearly no studies reported intracytoplasmic phagocytosis of PP particles or disintegration of PP material. One reason for this difference may be the time of observation. Most in vivo studies only cover time intervals of up to three months. In this study, disintegration and phagocytosis of PP particles did not become relevant until 3 months. Furthermore, unlike common histological procedures, the method of embedding in methacrylate used in this study 
Table II. Results of the histological analysis. Percentage of surviving animals treated with Medpor or Synpor and presenting signs of acute or chronic inflammation, foreign body giant cells, phagocytosis, disintegration or fibrovascular obliteration. No signs of severe acute or chronic inflammation were observed. Note that signs of acute inflammation decreased over time whereas signs of chronic inflammation, fibrovascular obliteration and foreign body reaction combined with phagocytosis and implant disintegration increased over time without major differences between both PP groups.

\begin{tabular}{|c|c|c|c|c|c|c|c|c|}
\hline \multirow[t]{2}{*}{ Pathological sign } & \multicolumn{2}{|c|}{1 week } & \multicolumn{2}{|c|}{4 weeks } & \multicolumn{2}{|c|}{3 months } & \multicolumn{2}{|c|}{6 months } \\
\hline & $\begin{array}{c}\text { Medpor } \\
(10 \text { animals })\end{array}$ & $\begin{array}{c}\text { Synpor } \\
(10 \text { animals })\end{array}$ & $\begin{array}{c}\text { Medpor } \\
(10 \text { animals })\end{array}$ & $\begin{array}{c}\text { Synpor } \\
(10 \text { animals })\end{array}$ & $\begin{array}{l}\text { Medpor } \\
\text { (7 animals) }\end{array}$ & $\begin{array}{c}\text { Synpor } \\
(9 \text { animals })\end{array}$ & $\begin{array}{c}\text { Medpor } \\
(10 \text { animals })\end{array}$ & $\begin{array}{c}\text { Synpor } \\
(9 \text { animals })\end{array}$ \\
\hline \multicolumn{9}{|c|}{ Acute inflammation } \\
\hline None & $60 \%$ & $10 \%$ & $0 \%$ & $0 \%$ & $85.7 \%$ & $88.9 \%$ & $60 \%$ & $77.8 \%$ \\
\hline Low-grade & $40 \%$ & $90 \%$ & $100 \%$ & $100 \%$ & $14.3 \%$ & $11.1 \%$ & $40 \%$ & $22.2 \%$ \\
\hline Medium-grade & $0 \%$ & $0 \%$ & $0 \%$ & $0 \%$ & $0 \%$ & $0 \%$ & $0 \%$ & $0 \%$ \\
\hline \multicolumn{9}{|c|}{ Chronic inflammation } \\
\hline None & $40 \%$ & $20 \%$ & $50 \%$ & $80 \%$ & $0 \%$ & $0 \%$ & $10 \%$ & $0 \%$ \\
\hline Low-grade & $50 \%$ & $80 \%$ & $50 \%$ & $20 \%$ & $100 \%$ & $100 \%$ & $90 \%$ & $66.7 \%$ \\
\hline Medium-grade & $10 \%$ & $0 \%$ & $0 \%$ & $0 \%$ & $0 \%$ & $0 \%$ & $0 \%$ & $33.3 \%$ \\
\hline \multicolumn{9}{|c|}{ Foreign body giant cells } \\
\hline None & $0 \%$ & $0 \%$ & $10 \%$ & $0 \%$ & $0 \%$ & $0 \%$ & $0 \%$ & $11.1 \%$ \\
\hline Sporadic & $100 \%$ & $100 \%$ & $40 \%$ & $50 \%$ & $71.4 \%$ & $66.7 \%$ & $60 \%$ & $11.1 \%$ \\
\hline Many & $0 \%$ & $0 \%$ & $50 \%$ & $50 \%$ & $28.6 \%$ & $33.3 \%$ & $40 \%$ & $77.8 \%$ \\
\hline \multicolumn{9}{|c|}{ Phagocytosis of PP particles } \\
\hline None & $70 \%$ & $100 \%$ & $60 \%$ & $90 \%$ & $57.1 \%$ & $44.4 \%$ & $70 \%$ & $55.6 \%$ \\
\hline Low-grade & $30 \%$ & $0 \%$ & $40 \%$ & $10 \%$ & $42.9 \%$ & $55.6 \%$ & $30 \%$ & $44.4 \%$ \\
\hline \multicolumn{9}{|l|}{ Disintegration } \\
\hline None & $60 \%$ & $40 \%$ & $100 \%$ & $90 \%$ & $28.6 \%$ & $22.2 \%$ & $80 \%$ & $44.4 \%$ \\
\hline Low-grade & $40 \%$ & $60 \%$ & $0 \%$ & $10 \%$ & $71.4 \%$ & $77.8 \%$ & $20 \%$ & $55.6 \%$ \\
\hline \multicolumn{9}{|c|}{ Fibrovascular obliteration } \\
\hline Incomplete & $10 \%$ & $0 \%$ & $100 \%$ & $90 \%$ & $0 \%$ & $0 \%$ & $0 \%$ & $0 \%$ \\
\hline Complete & $90 \%$ & $100 \%$ & $0 \%$ & $10 \%$ & $100 \%$ & $100 \%$ & $100 \%$ & $100 \%$ \\
\hline
\end{tabular}

allows easier detection of disintegrated polyethylene particles. In a case series, Patel et al. excised parts of previously implanted orbital floor implants made of PP (50). The healing periods from insertion to sampling ranged from 5 months to two years. The authors recognized a mild chronic inflammatory and foreign body reaction including foreign body giant cells. They also found evidence for porous polyethylene particles using polarized light.

In this study, animals in the Medpor group showed a significantly higher increase in systemic inflammatory cytokine expression (IL-6, IL-12 and INF- $\gamma$ ) than animals treated with Synpor implants. However, apart from IL-6 in the Medpor group, expression of all investigated cytokines dropped to nonsignificant levels in week 24 . The expression of TNF- $\alpha$ did not increase in both groups. Furthermore, a significant increase in the expression of TNF- $\alpha$ of unknown origin was determined in the negative control group throughout the whole observation period. It has to be mentioned critically that neither an increase nor a decrease in the expression of inflammatory cytokines was correlated to any histological results.

Apart from that, histological evaluations in several studies cast doubt on the long-term biocompatibility and stability of implants made of PP $(24,25,33)$. Biologically active coatings by glykoproteins, hormones, growth factors or extracellular matrix components are recent approaches to overcome rejection reactions against implants made of PP. Ehrmantraut et al. coated PP samples with platelet-rich plasma and a suspension of human chondrocytes and inserted them into dorsal skinfold chambers of CD-1 nude mice (51). They found an accelerated and intensified vascularization around coated implants compared to un-coated implants. Additionally, they determined less foreign body giant cells and macrophages around coated implants and proposed that the chondrocytes may form a bioprotective tissue layer. In another recent study, PP surfaces were coated using vitronectin, a matricellular glycoprotein (52). Histologically, surface coating accelerated and intensified peri-implant vascularization in mice by enhancing the maturation process of vessels. The authors concluded that coating of PP with vitronectin may be a way to increase biocompatibility in areas with low blood supply. In another recent in vivo study, Hussain et al. used syngeneic GFP-transfected dermal fibroblasts to coat PP implants and inserted them into skinfold chambers of $\mathrm{C} 57 \mathrm{Bl} / 6$ mice (53). After 10 days, they found that $69 \%$ of the fibroblasts were still detectable in mice that received the coated implants. However, angiogenic 


\section{Systemic cytokine expression in vivo}

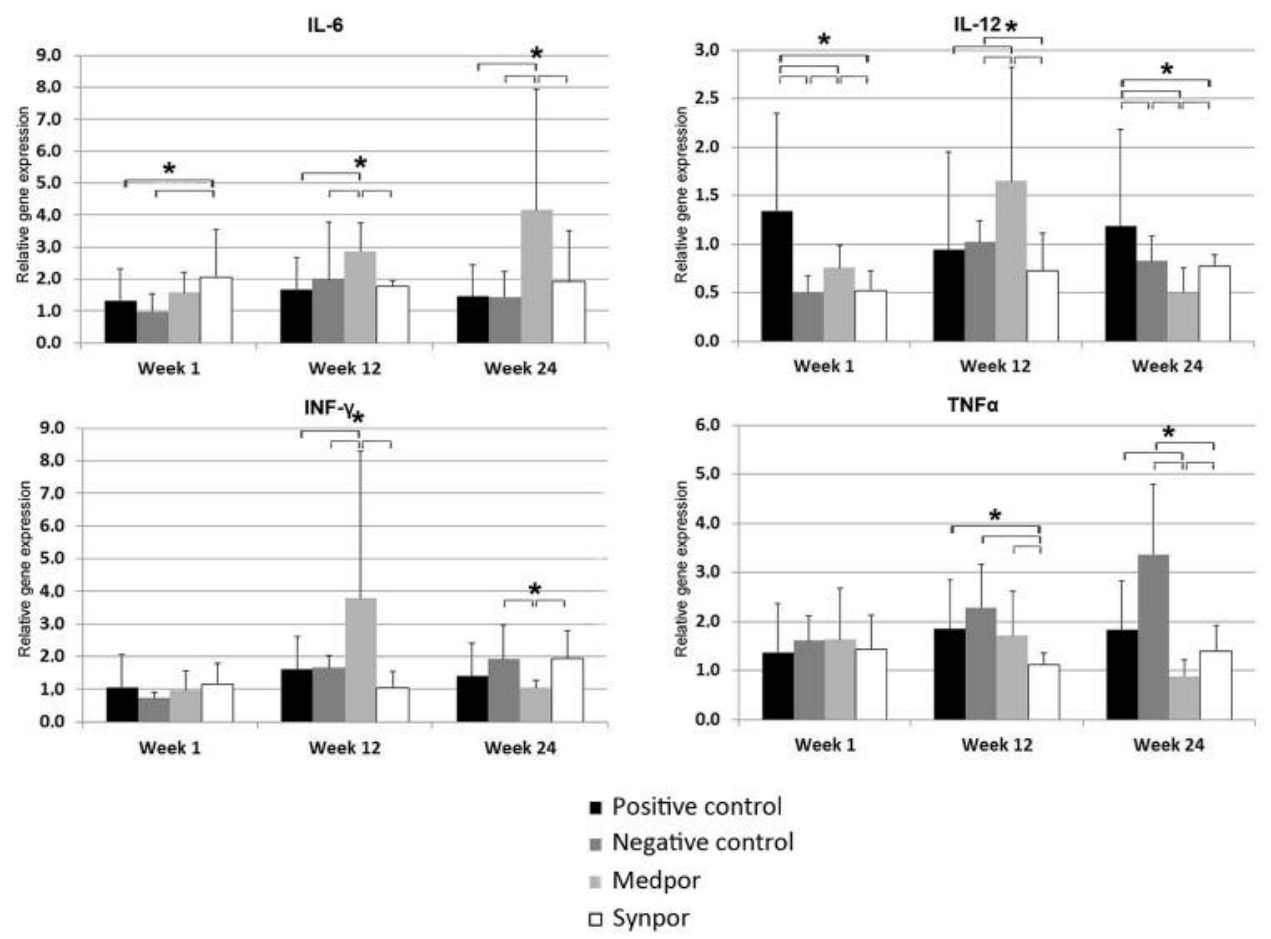

Figure 6. Relative gene expression of inflammation marker genes in murine spleen tissue of control and test groups after 1 week, 12 weeks and 24 weeks \pm standard deviation; $* p<0.05$.

parameters increased in mice with coated implants as well as in mice that received un-coated PP implants. Cytokine expression of IL-2, IL-10 and IL-17 increased after insertion of the materials without significant differences between both groups. Garibaldi et al. coated PP with polyvinyl alcohol and triamcinolone acetonide matrix (54). The coated PP implants were inserted in the posterior eyelid lamella of rabbits. After 12 weeks, fibrovascular ingrowth was prevented and coated implants presented less inflammation and capsule vascularity in comparison to non-coated implants. The authors concluded that coating with polyvinyl alcohol and triamcinolone acetonide might prevent lower eyelid retraction when PP is used as spacer. Other studies showed that local application of macrophage-activating lipopeptide- 2 or coatings with components of the plasminogen activation system could stimulate and accelerate the early vascularization of PP implants $(55,56)$. Despite the depicted effects, it would be of interest whether or not any bioactive coating could reduce foreign body giant cell reactions or implant disintegration as determined in this study.

Implants made of titanium, ceramics or bioactive glass are alternatives to porous polyethylene concerning hard tissue reconstruction $(57,58)$. Those implants can be manufactured patient-specific and show only minor foreign body reactions
(59). Furthermore, patient-specific implants allow for precise reconstructions and can be considered as a serious alternative to manually bent implants (60). Taking bone reconstruction into consideration, these implant materials are usually superior to PP, but in the nose, eyelid or ear reconstruction as well as facial augmentation they are no alternatives because of haptics, soft tissue behavior and the limited possibility of contouring. Besides ceramics, titanium and bioactive glass, polyetheretherketone (PEEK) implants offer an additional option in reconstructive cranio-maxillo-facial and aesthetic surgery (61). PEEK implants can also be planned and fabricated individually with good aesthetic results (62). However, similar to PP they also show foreign body reactions (63).

To conclude, porous polyethylene implants can cause local chronic inflammatory reactions, but no general lasting immune response. However, although clinical use of implants made of porous polyethylene seems to be safe, indication, chances and risks should be carefully evaluated prior to application. The current understanding of PP as a biomaterial is not yet sophisticated enough to confirm absolute long-term biostability. Further research is necessary in order to reduce the risks of chronic inflammation, infection, extrusion and disintegration. 


\section{Acknowledgements}

This work was funded by the AO Foundation (grant S-10-3G). The authors declare no conflicts of interest.

\section{References}

1 Ali K, Trost JG, Truong TA and Harshbarger RJ, 3rd: Total ear reconstruction using porous polyethylene. Semin Plast Surg 31(3): 161-172, 2017.

2 Wang JC, Wei L, Xu J, Liu JF and Gui L: Clinical outcome of cranioplasty with high-density porous polyethylene. J Craniofac Surg 23(5): 1404-1406, 2012.

3 Lin J and Chen X: Modified technique of chin augmentation with medpor for asian patients. Aesthet Surg J 32(7): 799-803, 2012.

4 Kumar NG, Sreenivas M and Gowda S: Cranioplasty of large cranial defects with porous polyethylene implants. J Craniofac Surg 27(4): e333-335, 2016.

5 Wellisz T: Clinical experience with the medpor porous polyethylene implant. Aesthetic Plast Surg 17(4): 339-344, 1993.

6 Morton AD, Nelson C, Ikada Y and Elner VM: Porous polyethylene as a spacer graft in the treatment of lower eyelid retraction. Ophthalmic Plast Reconstr Surg 16(2): 146-155, 2000.

7 Mueller S, Ihrler S and Ehrenfeld M: Facial reconstructions with medpor: First experiences. J Craniomaxillofacial Surg 34(1): 53, 2006.

8 Potter JK, Malmquist $\mathrm{M}$ and Ellis E, 3rd: Biomaterials for reconstruction of the internal orbit. Oral Maxillofac Surg Clin North Am 24(4): 609-627, 2012.

9 Ozturk S, Sengezer M, Isik S, Turegun M, Deveci M and Cil Y: Long-term outcomes of ultra-thin porous polyethylene implants used for reconstruction of orbital floor defects. J Craniofac Surg 16(6): 973-977, 2005.

10 Lee $\mathrm{H}$ and Baek S: Comparison of early fibrovascular proliferation according to orbital implant in orbital floor fracture reconstruction. J Craniofac Surg 23(5): 1518-1523, 2012.

11 Skouras A, Skouras G, Karypidis D and Asimakopoulou FA: The use of medpor(c) alloplastic material in rhinoplasty: Experience and outcomes. J Plast Reconstr Aesthet Surg 65(1): 35-42, 2012.

12 Niechajev I: Porous polyethylene implants for nasal reconstruction: Clinical and histologic studies. Aesthetic Plast Surg 23(6): 395402, 1999.

13 Tsiliboti D, Antonopoulos D, Spyropoulos K, Naxakis S and Goumas P: Total nasal reconstruction using a prelaminated free radial forearm flap and porous polyethylene implants. J Reconstr Microsurg 24(6): 449-452, 2008.

14 Colletti G, Saibene AM, Giannini L, Dessy M, Deganello A, Pipolo C, Allevi F, Lozza P, Felisati G and Biglioli F: Endoscopic endonasal repair with polyethylene implants in medial orbital wall fractures: A prospective study on 25 cases. J Craniomaxillofac Surg 46(2): 274-282, 2018.

15 Ridwan-Pramana A, Wolff J, Raziei A, Ashton-James CE and Forouzanfar T: Porous polyethylene implants in facial reconstruction: Outcome and complications. J Craniomaxillofac Surg 43(8): 1330-1334, 2015.

16 Robiony M, Costa F, Demitri V, Crimi V and Politi M: Clinical experience with medpor implants in esthetic orthognatic surgery. J Craniomaxillofac Surg 24: 95-96, 1996.
17 Choi JC, Sims CD, Casanova R, Shore JW and Yaremchuk MJ: Porous polyethylene implant for orbital wall reconstruction. J Craniomaxillofac Trauma 1(3): 42-49, 1995.

18 Wolfe SA, Posnick JC, Yaremchuk MJ and Zide BM: Chin augmentation. Aesthet Surg J 24(3): 247-256, 2004.

19 Yaremchuk MJ: Facial skeletal reconstruction using porous polyethylene implants. Plast Reconstr Surg 111(6): 1818-1827, 2003.

20 Yaremchuk MJ: Infraorbital rim augmentation. Plast Reconstr Surg 107(6): 1585-1595, 2001

21 Yaremchuk MJ: Mandibular augmentation. Plast Reconstr Surg 106(3): 697-706, 2000.

22 Yaremchuk MJ and Israeli D: Paranasal implants for correction of midface concavity. Plast Reconstr Surg 102(5): 1676-1684, 1998.

23 Liang X, Wang K, Malay S, Chung KC and Ma J: A systematic review and meta-analysis of comparison between autologous costal cartilage and alloplastic materials in rhinoplasty. J Plast Reconstr Aesthet Surg 71: 1164-1173, 2018.

24 Peled ZM, Warren AG, Johnston P and Yaremchuk MJ: The use of alloplastic materials in rhinoplasty surgery: A meta-analysis. Plast Reconstr Surg 121(3): 85e-92e, 2008.

25 de Moraes Ferreira AC, Munoz XM, Okamoto R, Pellizer EP and Garcia IR Jr.: Postoperative complications in craniomaxillofacial reconstruction with medpor. J Craniofac Surg 27(2): 425-428, 2016.

26 Gaudin R, Knipfer C, Henningsen A, Smeets R, Heiland M and Hadlock T: Approaches to peripheral nerve repair: Generations of biomaterial conduits yielding to replacing autologous nerve grafts in craniomaxillofacial surgery. Biomed Res Int 2016: 3856262, 2016.

27 Laschke MW, Augustin V, Kleer S, Tschernig T and Menger MD: Locally applied macrophage-activating lipopeptide-2 (malp-2) promotes early vascularization of implanted porous polyethylene (medpor(r)). Acta Biomater 10(11): 4661-4669, 2014.

28 Mavrikakis I, Francis N, Poitelea C, Parkin B, Brittain P and Olver J: Medpor lower eyelid spacer: Does it biointegrate? Orbit 28(1): 58-62, 2009.

29 Anderson JM, Rodriguez A and Chang DT: Foreign body reaction to biomaterials. Semin Immunol 20(2): 86-100, 2008.

30 DeFife KM, Jenney CR, McNally AK, Colton E and Anderson JM: Interleukin-13 induces human monocyte/macrophage fusion and macrophage mannose receptor expression. J Immunol 158(7): 3385-3390, 1997

31 Ibrahim M, Bond J, Medina MA, Chen L, Quiles C, Kokosis G, Bashirov L, Klitzman B and Levinson H: Characterization of the foreign body response to common surgical biomaterials in a murine model. Eur J Plast Surg 40(5): 383-392, 2017.

$32 \mathrm{Kim}$ YH, Kim BJ and Jang TY: Use of porous high-density polyethylene (medpor) for spreader or extended septal graft in rhinoplasty: Aesthetics, functional outcomes, and long-term complications. Ann Plast Surg 67(5): 464-468, 2011.

33 Gosau M, Draenert FG and Ihrler S: Facial augmentation with porous polyethylene (medpor)--histological evidence of intense foreign body reaction. J Biomed Mater Res B Appl Biomater 87(1): 83-87, 2008.

34 Gosau M, Schiel S, Draenert GF, Ihrler S, Mast G and Ehrenfeld $\mathrm{M}$ : [craniofacial augmentation with porous polyethylene implants (medpor: First clinical results]. Mund Kiefer Gesichtschir 10(3): 178-184, 2006. 
35 Draenert GF, Doeblinger M, Draenert M and Gosau M: Highdensity polyethylene facial implants show surface oxidation in sem and edx examination: A pilot study. Acta Biomater 5(4): 1158-1162, 2009.

36 Kilkenny C, Browne WJ, Cuthill IC, Emerson M and Altman DG: Improving bioscience research reporting: The arrive guidelines for reporting animal research. PLoS Biol 8(6): e1000412, 2010.

37 Gaber JC, Barbee RW, Bielitzki JT, Clayton LA, Donovan JC, Hendriksen CFM, Kohn DF, Lipman NS, Locke PA, Melcher J, Quimby FW, Turner PV, Wood GA and Würbel H: Guide for the care and use of laboratory animals. 8th edn. National Academies Press: Washington, DC, 2011.

38 Godek ML, Duchsherer NL, McElwee Q and Grainger DW: Morphology and growth of murine cell lines on model biomaterials. Biomed Sci Instrum 40: 7-12, 2004.

39 Klopfleisch R: Macrophage reaction against biomaterials in the mouse model - phenotypes, functions and markers. Acta Biomater 43: 3-13, 2016.

40 Fang RC and Mustoe TA: Animal models of wound healing: Utility in transgenic mice. J Biomater Sci Polym Ed 19(8): 9891005, 2008.

41 Krzyszczyk P, Schloss R, Palmer A and Berthiaume F: The role of macrophages in acute and chronic wound healing and interventions to promote pro-wound healing phenotypes. Front Physiol 9: 419, 2018.

42 Mantovani A, Sica A, Sozzani S, Allavena P, Vecchi A and Locati M: The chemokine system in diverse forms of macrophage activation and polarization. Trends Immunol 25(12): 677-686, 2004.

43 Badylak SF, Valentin JE, Ravindra AK, McCabe GP and StewartAkers AM: Macrophage phenotype as a determinant of biologic scaffold remodeling. Tissue Eng Part A 14(11): 1835-1842, 2008.

44 Choee JH, Lee SJ, Lee YM, Rhee JM, Lee HB and Khang G: Proliferation rate of fibroblast cells on polyethylene surfaces with wettability gradient. J Appl Polym Sci 92: 599-606, 2004.

45 Shanbhag AS, Jacobs JJ, Glant TT, Gilbert JL, Black J and Galante JO: Composition and morphology of wear debris in failed uncemented total hip replacement. J Bone Joint Surg Br 76(1): 60-67, 1994.

46 Rader CP, Sterner T, Jakob F, Schutze N and Eulert J: Cytokine response of human macrophage-like cells after contact with polyethylene and pure titanium particles. J Arthroplasty 14(7): 840-848, 1999.

47 Man K, Jiang LH, Foster R and Yang XB: Immunological responses to total hip arthroplasty. J Funct Biomater 8(3), 2017. doi: 10.3390/jfb8030033.

48 Draenert FG, Gosau M and Doeblinger M: High-density polyethylene facial implants show oxidation. J Craniomaxillofac Surg 36(1): S3, 2008.

49 Chuo JY, Dolman PJ, Ng TL, Buffam FV and White VA: Clinical and histopathologic review of 18 explanted porous polyethylene orbital implants. Ophthalmology 116(2): 349-354, 2009.

50 Patel PJ, Rees HC and Olver JM: Clinicopathologic reports, case reports, and small case series: Fibrovascularization of porous polyethylene orbital floor implants in humans. Arch Ophthalmol 121(3): 400-403, 2003.

51 Ehrmantraut S, Naumann A, Willnecker V, Akinyemi S, Korbel C, Scheuer C, Meyer-Lindenberg A, Menger MD and Laschke MW: Vitalization of porous polyethylene (medpor(r)) with chondrocytes promotes early implant vascularization and incorporation into the host tissue. Tissue Eng Part A 18(15-16): 1562-1572, 2012.

52 Hessenauer MET, Lauber K, Zuchtriegel G, Uhl B, Hussain T, Canis M, Strieth S, Berghaus A and Reichel CA: Vitronectin promotes the vascularization of porous polyethylene biomaterials. Acta Biomater 82: 24-33, 2018.

53 Hussain T, Schneider M, Summer B and Strieth S: Pre-operative in vitro fibroblast coating of porous polyethylene compound grafts - cell survival in vivo and effects on biocompatibility. Biomed Mater Eng 27(2-3): 237-249, 2016.

54 Garibaldi DC, Robinson MR, Lee SS, Park DJ, Fine HF, Deitz L, D'Anna S, Yuan P, Ranson N, Grant MP, Iliff NT and Merbs SL: New corticosteroid-eluting porous polyethylene implant for the management of lower eyelid retraction: A pilot study. Ophthalmic Plast Reconstr Surg 22(6): 424-429, 2006.

55 Laschke MW, Augustin VA, Sahin F, Anschutz D, Metzger W, Scheuer C, Bischoff M, Aktas C and Menger MD: Surface modification by plasma etching impairs early vascularization and tissue incorporation of porous polyethylene (medpor((r))) implants. J Biomed Mater Res B Appl Biomater 104(8): 1738$1748,2016$.

56 Reichel CA, Hessenauer ME, Pflieger K, Rehberg M, Kanse SM, Zahler S, Krombach F, Berghaus A and Strieth S: Components of the plasminogen activation system promote engraftment of porous polyethylene biomaterial via common and distinct effects. PLoS One 10(2): e0116883, 2015.

57 Peng MY, Merbs SL, Grant MP and Mahoney NR: Orbital fracture repair outcomes with preformed titanium mesh implants and comparison to porous polyethylene coated titanium sheets. J Craniomaxillofac Surg 45(2): 271-274, 2017.

58 Kinnunen I, Aitasalo $\mathrm{K}$, Pollonen $\mathrm{M}$ and Varpula $\mathrm{M}$ : Reconstruction of orbital floor fractures using bioactive glass. J Craniomaxillofac Surg 28(4): 229-234, 2000.

59 Zielinski R, Malinska M and Kozakiewicz M: Classical versus custom orbital wall reconstruction: Selected factors regarding surgery and hospitalization. J Craniomaxillofac Surg 45(5): 710715, 2017.

60 Gander T, Essig H, Metzler P, Lindhorst D, Dubois L, Rucker $M$ and Schumann P: Patient specific implants (psi) in reconstruction of orbital floor and wall fractures. $\mathbf{J}$ Craniomaxillofac Surg 43(1): 126-130, 2015.

61 Alonso-Rodriguez E, Cebrian JL, Nieto MJ, Del Castillo JL, Hernandez-Godoy $\mathrm{J}$ and Burgueno M: Polyetheretherketone custom-made implants for craniofacial defects: Report of 14 cases and review of the literature. J Craniomaxillofac Surg 43(7): 1232-1238, 2015.

62 Gerbino G, Zavattero E, Zenga F, Bianchi FA, Garzino-Demo P and Berrone S: Primary and secondary reconstruction of complex craniofacial defects using polyetheretherketone custommade implants. J Craniomaxillofac Surg 43(8): 1356-1363, 2015.

63 Stratton-Powell AA, Pasko KM, Brockett CL and Tipper JL: The biologic response to polyetheretherketone (peek) wear particles in total joint replacement: A systematic review. Clin Orthop Relat Res 474(11): 2394-2404, 2016.

Received December 6, 2018

Revised December 14, 2018 Accepted December 17, 2018 